NBER WORKING PAPER SERIES

\title{
THE EFFECTS OF PRODUCT LIABILITY EXEMPTION IN THE PRESENCE OF THE FDA
}

\author{
Tomas J. Philipson \\ Eric C. Sun \\ Dana Goldman
}

Working Paper 15603

http://www.nber.org/papers/w15603

\author{
NATIONAL BUREAU OF ECONOMIC RESEARCH \\ 1050 Massachusetts Avenue \\ Cambridge, MA 02138 \\ December 2009
}

Prepared for the NBER conference "Regulation and Litigation", Sep 11-12, 2009, Arizona. We are indebted to Yang Lu for excellent research assistance, the conference participants at the NBER Law and Economics conference, and two anonymous referees for comments and suggestions. Sun gratefully acknowledges funding from the Medical Scientist Training Program at the University of Chicago (NIGMS Grant number 5 T32 GM07281). The views expressed herein are those of the author(s) and do not necessarily reflect the views of the National Bureau of Economic Research.

NBER working papers are circulated for discussion and comment purposes. They have not been peerreviewed or been subject to the review by the NBER Board of Directors that accompanies official NBER publications.

(C) 2009 by Tomas J. Philipson, Eric C. Sun, and Dana Goldman. All rights reserved. Short sections of text, not to exceed two paragraphs, may be quoted without explicit permission provided that full credit, including $\odot$ notice, is given to the source. 
The Effects of Product Liability Exemption in the Presence of the FDA

Tomas J. Philipson, Eric C. Sun, and Dana Goldman

NBER Working Paper No. 15603

December 2009, Revised February 2010

JEL No. I1,I18,K32

\begin{abstract}
In the United States, drugs are jointly regulated by the US Food and Drug Administration, which oversees premarket clinical trials designed to ensure drug safety and efficacy, and the liability system, which allows patients to sue manufacturers for unsafe drugs. In this paper, we examine the potential welfare effects of this dual system aimed at ensuring the safety of medical products, and conclude that product liability exemptions for FDA regulated activities could raise economic efficiency. We show that while reductions in liability, such those associated with pre-emption, may lower welfare in the absence of the FDA, they may raise welfare in its presence. In the presence of the FDA, product liability may reduce efficiency by raising prices without pushing firms, who are already bound by the agency's requirements, to invest further in product safety. We consider as a case study the National Vaccine Injury Compensation Program, which sharply reduced vaccine manufacturer's liability in 1988. We find evidence that the program reduced prices without affecting vaccine safety, suggesting that liability reductions can enhance economic efficiency in the presence of the FDA.
\end{abstract}

Tomas J. Philipson

Irving B. Harris Graduate School

of Public Policy Studies

The University of Chicago

1155 E 60th Street

Chicago, IL 60637

and NBER

t-philipson@uchicago.edu

Eric C. Sun

University of Chiacago and RAND

1776 Main St

Santa Monica, CA 90401

ericsun@uchicago.edu
Dana Goldman

School of Policy, Planning and Development

University of Southern California

650 Childs Way, RGL 214

Los Angeles, CA 90089-0626

and NBER

dpgoldma@usc.edu 


\section{Section 1: Introduction}

In the United States, the safety and efficacy of drugs and medical devices are primarily regulated by the United States Food and Drug Administration (FDA) through pre-market activities, such as mandatory clinical testing, and post-market activities, such as the use of the Adverse Event Reporting System to monitor the incidence of adverse events. However, while the FDA is the primary and most visible regulator of drug safety, the presence of legal liability after a product has entered the market gives firms large incentives to provide safe drugs.

The overlap between the FDA and product liability in regulating drug safety has received substantial attention from policymakers, particularly in light of several high profile lawsuits against drug manufacturers, such as those involving the drug Vioxx (rofecoxib). ${ }^{2}$ Of particular interest has been the issue of pre-emption, which states that FDA approval of a drug's label, which lists the indications that the drug is approved to treat as well as warnings about any side effects, gives the manufacturer immunity against lawsuits based on state law. In 2006, this doctrine was formally adopted by the FDA through a modification in the Federal Register. The FDA's adoption of the pre-emption doctrine has been controversial in legal circles, with lower federal courts offering conflicting views on the doctrine. Recently, in Riegel v. Medtronic, the Supreme Court of the United States upheld the pre-emption doctrine for medical devices, although in a 5-4 decision in Wyeth v. Levine, the Court ruled the doctrine did not apply to drugs. Supporters of pre-emption argue that it frees pharmaceutical firms from the chaos of having 50 separate States regulate drug safety, thereby reducing the potential that pharmaceutical firms will "over-warn" patients about the risks of drugs (Calfee 2008; Calfee et al., 2008).

\footnotetext{
${ }^{2}$ Vioxx, a selective COX-2 inhibitor, was withdrawn from the US market in 2004 after several high profile lawsuits alleging that the drug significantly increased patients' risk of adverse cardiovascular events. On November 9, 2007, the manufacturer of Vioxx, Merck, agreed to establish a $\$ 4.85$ billion settlement fund to compensate Vioxx patients who experienced a myocardial infarction or ischemic stroke while using the drug.
} 
Opponents argue that product liability is a useful complement to the FDA, and has resulted in safer drugs (Kessler and Vladeck, 2008; Curfman, Morrisey, and Drazen, 2008; Glantz and Annas, 2008).

Despite the debate over the potential consequences of pre-emption, there has been little explicit economic analysis that has attempted to determine under what circumstances preemption, or limits on damages more generally, might improve economic efficiency. In this paper we provide a formal analysis of the dual regulation of medical product safety and the potential efficiency effects induced by product liability in the presence of the FDA. Our main argument is that the standard efficiency implications of product liability are altered when there is dual regulation of safety through another government agency such as the FDA. In particular, lowering liability (through pre-emption or other means) in the presence of the FDA can raise welfare under conditions when it would otherwise lower welfare in the agency's absence. Two central aspects of the FDA's activities drive these opposite effects. First, the FDA generates information about product quality prior to marketing beyond what would be the case with liability alone. Second, the FDA requires a minimum level of product quality before marketing.

As is well known, when consumers are fully informed about product quality, product liability cannot improve on an already efficient outcome. Any efficiency gains from either product liability or the FDA must therefore come from lack of full information about product quality on the demand side. When the demand side is uninformed, particularly when it underestimates the potential harms of a drug, product liability accomplishes two socially desirable actions. First, it helps provide the efficient level of quality or safety by giving firms incentives to provide safe products. Second, it ensures the efficient level of product quantity. 
Since consumers will over-consume a drug when they underestimate its risk, product liability acts as a beneficial tax.

However, by imposing and verifying a minimal safety level, the FDA addresses both of these issues directly. On the quality side, to the degree that the FDA's safety standards are binding on firms, product liability may not induce them to provide additional safety. In terms of quantity, since the FDA verifies safety, consumers are more informed, mitigating the concern of overconsumption. In the agency's presence, product liability thereby merely acts as a tax. Even if this tax is paid back to patients in the form of damages, a dead-weight loss still exists due to reduced access. Thus, while product liability may raise efficiency in the absence of the FDA by inducing firms to provide safety and appropriately restrict access, in the agency's presence it can actually reduce welfare by inappropriately reducing access. We offer an empirical test of the conditions under which increased liability may reduce efficiency through the quality-dimension that involves testing for changes in the price and safety effects of liability changes.

Clearly, our efficiency analysis for pre-emption should by no means be interpreted as abolishing product liability altogether, e.g. for fraud or activities for which FDA has no jurisdiction, but simply for those activities in which a public entity like the FDA is overseeing the same type of behavior as product liability—in these cases, the duplication of regulation and liability is inefficient. To reiterate, our arguments do not apply to all activities, just those for which there are dual government interventions.

We consider the National Vaccine Injury Compensation Program (NVICP) as a case study to illustrate how to test for the welfare effects of changes in liability. This program shielded vaccine makers from liability in exchange for a special compensation program funded by an excise tax on vaccines. This program therefore essentially mimicked pre-emption by 
lowering the cost of liability dramatically for manufacturers. Prior to the implementation of NVICP, there was a substantial increase in liability actions relating to vaccines, and this increase is associated with a rapid increase in prices. After the NVICP was implemented, prices fell. However, we find no evidence that the NVICP led to more unsafe vaccines. If the effects of this program are indicative of a more general pattern of no safety effects and reduced prices when reducing liability in presence of FDA, then pre-emption may be efficiency enhancing. The paper is briefly organized as follows. Section 2 provides background on the dual regulation of drug safety. Section 3 presents and discusses our analysis of the efficiency effects of pre-emption. Section 4 discusses our case studies for vaccines covered by the NVICP. Lastly, Section 5 concludes and discusses future research. 


\section{Section 2: Background on US Medical Product Safety Regulation.}

In the United States, the FDA is the federal agency charged with regulating drug safety and efficacy. The majority of the agency's efforts are devoted towards pre-market activities, whereby the agency supervises and evaluates a series of clinical trials undertaken by drug manufacturers in order to establish drug safety and efficacy. The clinical trial process begins when a firm files an Investigational New Drug application, which requests permission from the FDA to conduct clinical trials on humans. Typically, this application contains the available preclinical information, as well as protocols for the drug's clinical trials, and any data on trials conducted overseas.

Once the FDA gives its approval, the firm may begin conducting clinical trials for the drug, which proceed in three phases. The goal of Phase I is to evaluate the drug's safety and to obtain data on its pharmacologic properties. Typically, Phase I trials enroll small numbers (2080) of healthy volunteers. Phase II trials then enroll slightly larger (100-130) numbers of sick volunteers. The goal of these trials is to begin investigating a drug's efficacy and optimal dosage, and to monitor the drug's safety in diseased patents. Finally, Phase III testing typically involves larger numbers (more than 1,000) of sick patients and is the most costly stage of the approval process. Phase III testing seeks to establish more definitively the efficacy of a drug, as well as to discover any rare side effects. Upon the completion of Phase III testing, the firm submits a New Drug Application to the FDA, which is accompanied by the results of the clinical trials. The FDA may then reject the application, require further clinical testing, or approve the drug outright.

In addition to issuing approval of the drug, the FDA must approve the label that accompanies it. This label provides data on the drug's pharmacologic properties and side effects, 
as well as brief summaries of the clinical trials reported to the FDA. Perhaps most importantly, the label also lists the indications (or diseases) that the drug is approved to treat. Thus, approval by the FDA is not merely approval of the drug, it is approval of the drug for specific uses. If a firm wishes to obtain approval for additional indications, it typically must begin a new set of clinical trials for those indications. Use of a drug for an indication not listed on the label ("offlabel use") is not illegal, and indeed occurs regularly in many areas, such as oncology. However, it is illegal for a manufacturer to advertise a drug for a non-approved indication. In addition, insurers may not always pay for off-label use of a drug.

The FDA also oversees the safety and efficacy of medical devices. Here, the process is more complex, because the statutory definition of a medical device is extremely broad ${ }^{3}$ and includes a wide variety of implements, such as tongue depressors, home pregnancy tests, and drug eluting stents. All devices are categorized into one of three classes (I, II, and III), based on the degree of patient risk. Class I devices are the least risky, and typically require no premarket approval from the FDA, although the manufacturer must register with the FDA prior to marketing the device. Class II devices pose more risk to patients, and must receive prior approval via the $510(\mathrm{k})$ review process, which typically seeks to establish that the given device is substantially equivalent to another device that has received FDA approval. The most risky (class III) devices require approval via the premarket approval process (PMA), which, similar to the process for pharmaceuticals described above, involves the submission of a PMA application establishing the device's safety and efficacy, usually through the results of clinical trials. After

\footnotetext{
3 According to the Food, Drug and Cosmetic Act, a medical device is defined as "an instrument, apparatus, implement, machine, contrivance, implant, in vitro reagent, or other similar or related article, including any component, part, or accessory, which is (1) recognized in the official National Formulary, or the United States Pharmacopeia, or any supplement to them, (2) intended for use in the diagnosis of disease or other conditions, or in the cure, mitigation, treatment, or prevention of disease, in man or other animals, or (3) intended to affect the structure or any function of the body of man or other animals, and which does not achieve its primary intended purposes through chemical action within or on the body of man or other animals and which is not dependent upon being metabolized for the achievement of its primary intended purposes."
} 
receipt of a PMA or 510(k) application, the FDA reviews it and decides whether to allow the device to be marketed in the US. For devices approved via PMAs, further changes require different types of supplemental applications (supplemental PMAs), depending on the nature of the modification. Large-scale changes to the device, such as changes in its indication or substantial changes in design, require a Panel Track Supplement, which is in effect equivalent to submitting a new PMA. More modest changes require a 180-day Supplement, and minor modifications require a Real-time Supplement. In addition, changes in the manufacturing process must be approved via a 30-day Supplement.

While the FDA is the primary and most visible player in drug and device safety regulation, product liability also plays a role in ensuring safety by allowing patients to sue manufacturers for unsafe drugs or devices and recover damages for any adverse events that they suffer. Patients can generally sue manufacturers under one of three theories of legal liability. The first, defective design, allows a patient to sue on the basis that the design of a drug or device was inherently unsafe. Second, patients can sue for defective manufacturing of an otherwise safe drug or device. Finally, under the theory of defective warnings, patients can sue by showing that the firm failed to provide sufficient warning of the possibility of an adverse event if it knew or shown have known about the risks. Given that the FDA approval encompasses a drug or device's safety and the sufficiency of the warnings in the drug label, firms have tried to use FDA approval as a shield against product liability suits. For drugs, this argument has generally been accepted by the courts (Garber, 1993), under a widely cited comment included in Restatement (Second) of Torts, which states that drugs are an example of an "unavoidably unsafe product," in other words, drugs are not generally unreasonably dangerous, and the dangers associated with them are not evidence of defects in the drugs themselves. However, for medical devices, rather 
than drugs, design lawsuits are more common, since there is more ability to design a device with a better safety profile. Since courts have generally held that drug manufacturers cannot be sued for faulty design, the vast majority of drug lawsuits to date have been for failure to warn, and here, courts have in general held that FDA approval of the warnings on the label does not provide a shield against liability lawsuits. Courts have generally held that compliance with FDA regulations is a minimum standard. Thus, failure to comply with the FDA leaves a firm extremely vulnerable to lawsuits, but compliance does not shield a firm against lawsuits. However, it is important to note that the FDA maintains tight control over the information that a firm can release about a drug, including the release of warnings. For example, the FDA can prohibit the firm from adding a warning to the product label. Even if the FDA prohibits the firm from adding a warning, the firm can still be found liable for failing to warn consumers (Garber, 1993; Calfee, 2006). Lawsuits against firms proceed under state laws, and therefore, the determination of whether the firm knew, or should have known, about a particular risk is based on state-specific legal standards. If the patient prevails at the trial, he can recover compensatory damages for the adverse event, as well as punitive damages, if it is found that the firm intentionally hid evidence from the FDA.

While estimates of the costs of liability for pharmaceuticals and devices are few, there are indications that these costs are substantial, especially when viewed as a share of marginal costs. The latter is an important issue, as from an economic perspective, legal costs will have a larger effect on welfare when they comprise a large portion of marginal costs. Given that the marginal costs of drug production are low for drugs, even small legal costs may account for a significant proportion of marginal costs. A report prepared by the Council of Economic Advisers (2002) found that in 2000, liability costs across all US industries were $\$ 180$ billion, or roughly 1.8 
percent of GDP. The same report suggested that the inefficiencies from the liability system were equivalent to the inefficiencies that would occur from a 2 percent increase in consumption taxes, a 3 percent tax on wages, and a 5 percent tax on capital income.

There is research suggesting these relative liability costs are even higher for drugs. Manning (1994) identified liability costs for the diphtheria-pertussis-tetanus vaccine by comparing changes in the vaccine's price against changes in the price of the diphtheria-tetanus vaccine, as the only difference in the vaccines is the pertussis component, which adds a negligible cost to the production price of the vaccine and was the subject of numerous lawsuits. Using this approach, Manning found that liability accounted for up to $90 \%$ of the price of the diphtheria-pertussis-tetanus vaccine's price. In addition, in related work (Manning, 1997), Manning finds that differences in product liability regimes can explain much of the difference in the Canadian and US prices of drugs. 


\section{Section 3: An Efficiency Analysis of Regulation and Liability of Medical Products}

In this section, we analyze the efficiency effects of pre-emption. Our analysis begins in with a brief review of standard models of product liability (see Shavell, 2007; Polinsky and Shavell, 2007 for a review) which concern how post-market legal activities affect firms' safety and pricing decisions. It is well known that under perfect information, product liability has no effect on the level of safety firms provide or social welfare. Thus, the purpose of product liability is to give firms proper incentives to provide safety when consumers are uninformed. In addition, product liability helps achieve the optimal quantity in the face of consumer misinformation by affecting the prices that consumers pay.

We then add to this model the presence of pre-market regulations governed by the FDA. We assume that FDA (i) mandates and verifies a minimum safety level which may or may not be binding given the deterrence effect of product liability and (ii) that FDA generates information about product quality beyond what is generated under product liability alone. We show that these aspects of FDA may affect the sign of the efficiency effects of increased liability. Under perfect information about product quality, neither product liability nor any quality screening activities of the FDA will raise efficiency so we focus on the case of an uninformed demand side.

\subsection{The Framework}

Consider when marginal are constant and for a given level of safety $s$ are given by

$$
C(s)=c(s)+d(s)
$$

where $c(s)$ is the marginal cost of production that rises in safety and $d(s)$ is the marginal cost of legal costs that falls in safety. Our notion of safety $s$ is extremely flexible, and can accommodate 
a wide variety of specifications. For example, $s$ could refer to a vector of drug characteristics, such as the safety of the drug itself, as well as the adequacy of warnings about the drug. For the informed consumer, the inverse demand curve $p(q, s)$ is given by a component of a perfectly safe drug, $p(q)$ less the expected harm he faces given the drug's safety $h(s)$, plus the damages he expects to receive.

$$
p(q, s)=p(q)-h(s)+d(s)
$$

The demand curve adopts the form

$$
q(p, s)=q(p+h(s)-d(s))
$$

showing that the informed consumer treats the expected harm as a tax and the expected damages received as a subsidy. Social welfare is therefore given by

$$
W(q, s)=\int_{0}^{q(p, s)} p(x, s)-c(s)-h(s) d x
$$

While damage payments $d(s)$ do not directly enter the equation for social welfare, as they simply represent a transfer payment from firms to consumers, they may indirectly affect social welfare through their effects on price $p$ and therefore the quantity consumed $q(p, s)$.

\subsection{The Neutrality of Product Liability Under Perfect Information}

With perfectly informed consumers, the firm chooses the level of safety the maximizes its profit function, given by

$$
\pi(q, s)=q(p, s)(p-c(s)-d(s))
$$

It is easy to show that with perfect information, damages do not affect the firm's safety provision. Although damages enter into the firm's cost function, they also increase the consumer's valuation for the good by an equivalent amount. Therefore, in choosing the optimal 
safety level, the firm ignores the effect of damages on marginal costs and demand and simply chooses the safety level that equates the marginal revenue of increased safety with the marginal cost. Moreover, while damages raise the firms' costs and therefore price, they have no effect on output since consumers are aware in advance of the damages they receive. Thus, under perfect information, liability has no effect on social welfare or the firm's provision of safety.

\subsection{Product Liability with Uninformed Consumers}

Given that product liability and the FDA cannot have any welfare enhancing effects in the case of perfectly informed consumers we consider the case where consumers are uninformed. We assume that consumers under-estimate ${ }^{4}$ the harm of the product and are uninformed of damages so that the inverse demand curve is simply $p(q)$. Under these assumptions, the firm's profit function is given by

$$
\pi(p, s)=q(p)(p-c-c(s)-d(s))
$$

The first order condition for the optimal level of safety under product liability, denoted $s^{P L}$, is then given by

$$
c_{s}+d_{s}=0
$$

This simply states that the firm chooses the level of safety that minimizes costs through equating increased costs of production with reduced liabilities. Social welfare is now given by

$$
\int_{0}^{q(p)} p(x, s)-c(s)-h(s) d x
$$

which stands in contrast to social welfare under perfect information in that the total quantity consumed is now determined by the uninformed demand curve $q(p)$.

\footnotetext{
${ }^{4}$ Clearly, if consumers over-estimate harm, this would strengthen our arguments, as in this case quantity is already undersupplied.
} 
The effect of product liability on welfare is twofold. In terms of product quality, it gives firms incentive to provide safety by forcing them to internalize the costs of safety-clearly, they would have no such incentives in the absence of product liability with uninformed consumers. Second, for a given level of safety, product liability affects quantity as shown in Figure 1 . This figure plots the uninformed demand curve $q(p)$, the cost of production $c(s)$, the firm's marginal cost $c(s)+d(s)$, and the social cost of the good which is the cost of production plus the expected harm, $c(s)+h(s)$. The socially optimal consumption level occurs when price equals social cost (point A). However, in the absence of product liability, consumption occurs where price equals the marginal cost of production (point B). As shown in the figure, product liability therefore acts as a Pigouvian tax that reduces overconsumption by having consumers internalize the expected harm (point C). Indeed, optimal consumption is attained by setting damages $d(s)$ equal to expected harm $h(s)$ so that points $\mathrm{C}$ and A converge. 


\section{Figure 1 - Welfare Under Product Liability}

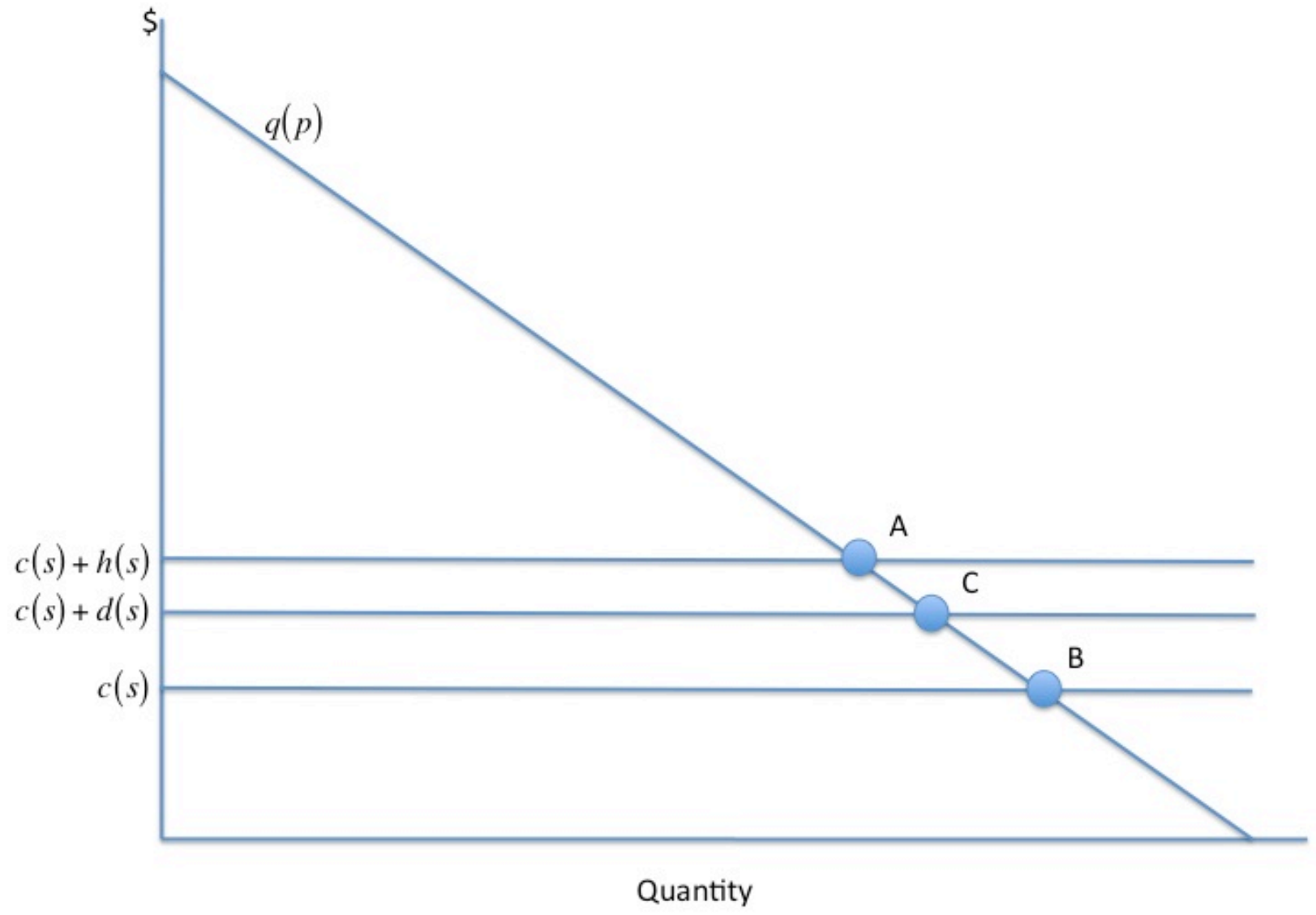

\subsection{Product Liability with the FDA}

The previous section discussed the traditional efficiency role of product liability to give firms incentives to provide levels of safety by facing firms with the social cost associated with unsafe products. To extend our analysis to incorporate the FDA, suppose that the agency mandates and monitors a minimal level of safety denoted $s^{F D A}$. For example this minimum level of safety could refer to product design, manufacturing practices, or the adequacy and timeliness of warnings about adverse effects. With the addition of the FDA, there are now two possibilities. If the level of safety the firm chooses to provide under product liability is higher than the level mandated by the FDA, then the firm will continue to provide the safety level $s^{P L}$ and in this case, 
the addition of the FDA has no safety-effects. However, if $s^{P L}$ is less than $s^{F D A}$, then the firm will provide the minimal level of safety enforced by the FDA. We refer to the latter case as a situation where the FDA mandated level of safety is binding on firms. Thus, if product liability alone, perhaps through imperfect enforcement or under-estimation of risks, does not give firms sufficient incentives to provide safety, the addition of the FDA can improve safety if the FDA mandates a level of safety higher than what firms would choose to provide under product liability alone.

Figure 2 - Welfare under Product Liability and the FDA

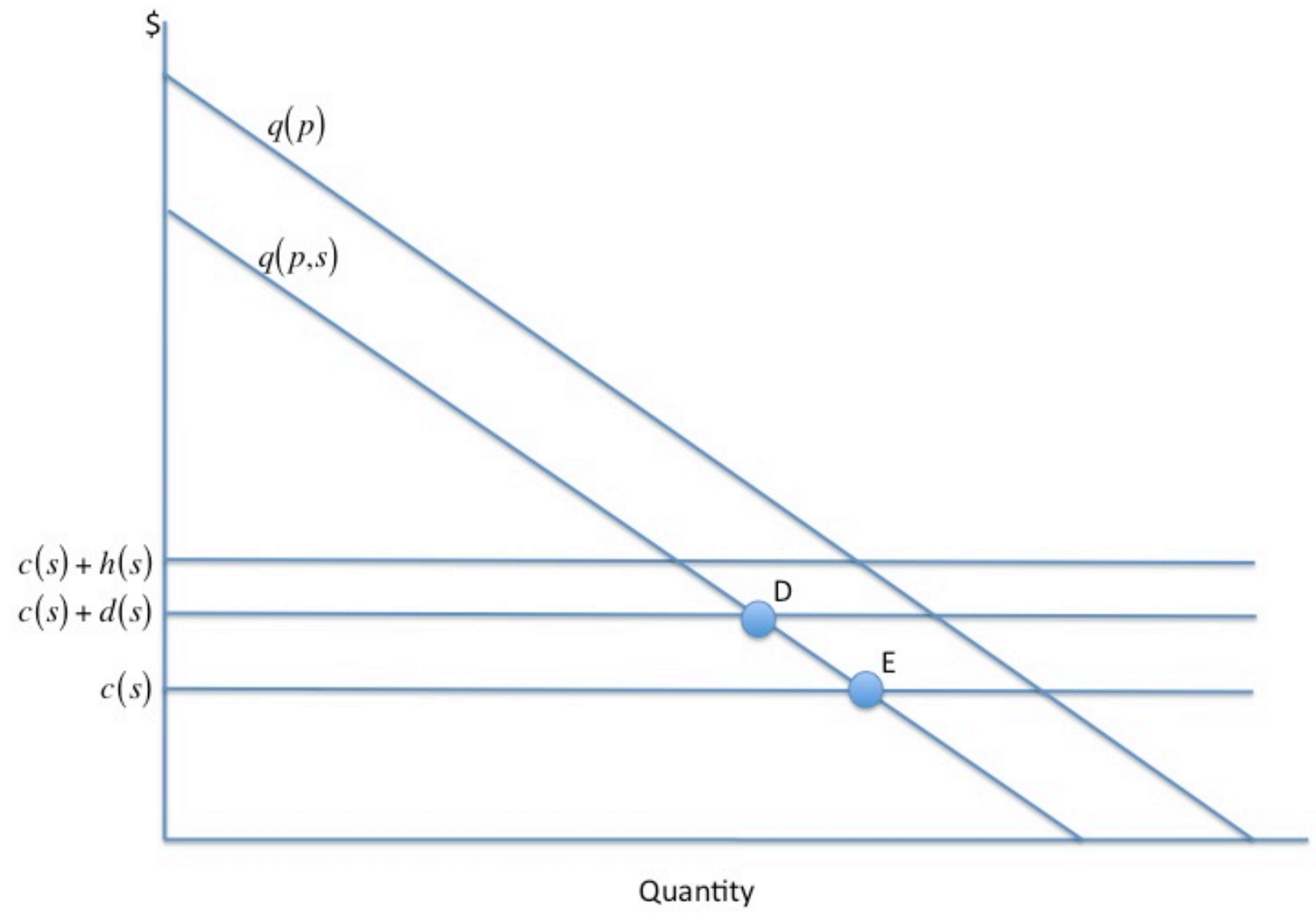


In the face of a binding FDA, the effects of product liability on safety and output are now different. If the FDA's regulations are binding, then by definition product liability has no additional effect on the firm's provision of safety. The effects on output are shown in Figure 2. We assume that the FDA verifies safety and provides information prior to marketing so that patients are informed about safety but not about the damages they receive ${ }^{5}$. In that case, the demand curve for the good $q(p, s)$ is the uninformed demand curve $q(p)$ shifted down by the expected harm $h(s)$, and the socially optimal level of consumption occurs where the informed demand curve meets the marginal cost of production (point E). As shown in Figure 2, product liability in the face of the FDA now leads to an inefficiently low level of output (point D). When consumers are uninformed, product liability acts as a Pigouvian tax that serves a social benefit by pricing in the expected harm of the drug. However, when the FDA provides safety information prior to marketing product liability simply serves as an additional tax that reduces output with a dead-weight loss. The presence of the FDA therefore affects the sign of the impact on efficiency by increased liability.

\subsection{The Welfare Effects of Pre-emption}

The pre-emption doctrine, as described in the introduction, would allow FDA approval to shield firms from lawsuits based on state law. In effect, the doctrine would set legal costs $d(s)$ equal to zero if the firm provided safety at least as high as the FDA mandated level. To analyze the effect of a product liability exemption on welfare, consider Figure 3 below, where the $\mathrm{x}$-axis shows the level of safety $s$ and the U-shaped curve $C(s)$ is the firm's costs. The optimal choice of safety

\footnotetext{
${ }^{5}$ Note that even if consumers are informed about safety, if they are uninformed about damages, then the legal regime $d(s)$ will affect the firm's safety provision, since damages raise the firm's costs without affecting consumers' valuation of the good.
} 
chosen by the firm $s^{P L}$ is the bottom of $C(s)$ (point A), where the marginal cost of producing safety equals the marginal benefits in terms of reduced liability costs. Under a regime that lowers product liability, the cost curve shifts to $C^{0}(s)$, which differs from the initial cost curve in two dimensions. First, costs are lower under $C^{0}(s)$, since firms pay lower liability costs.

Second, with the reduced liability, the optimal level of safety is reduced to $s^{P L 0}$. The firm's costs are therefore given by point B.

Figure 3 - Product Liability Exemption and Social Welfare: non-Binding FDA

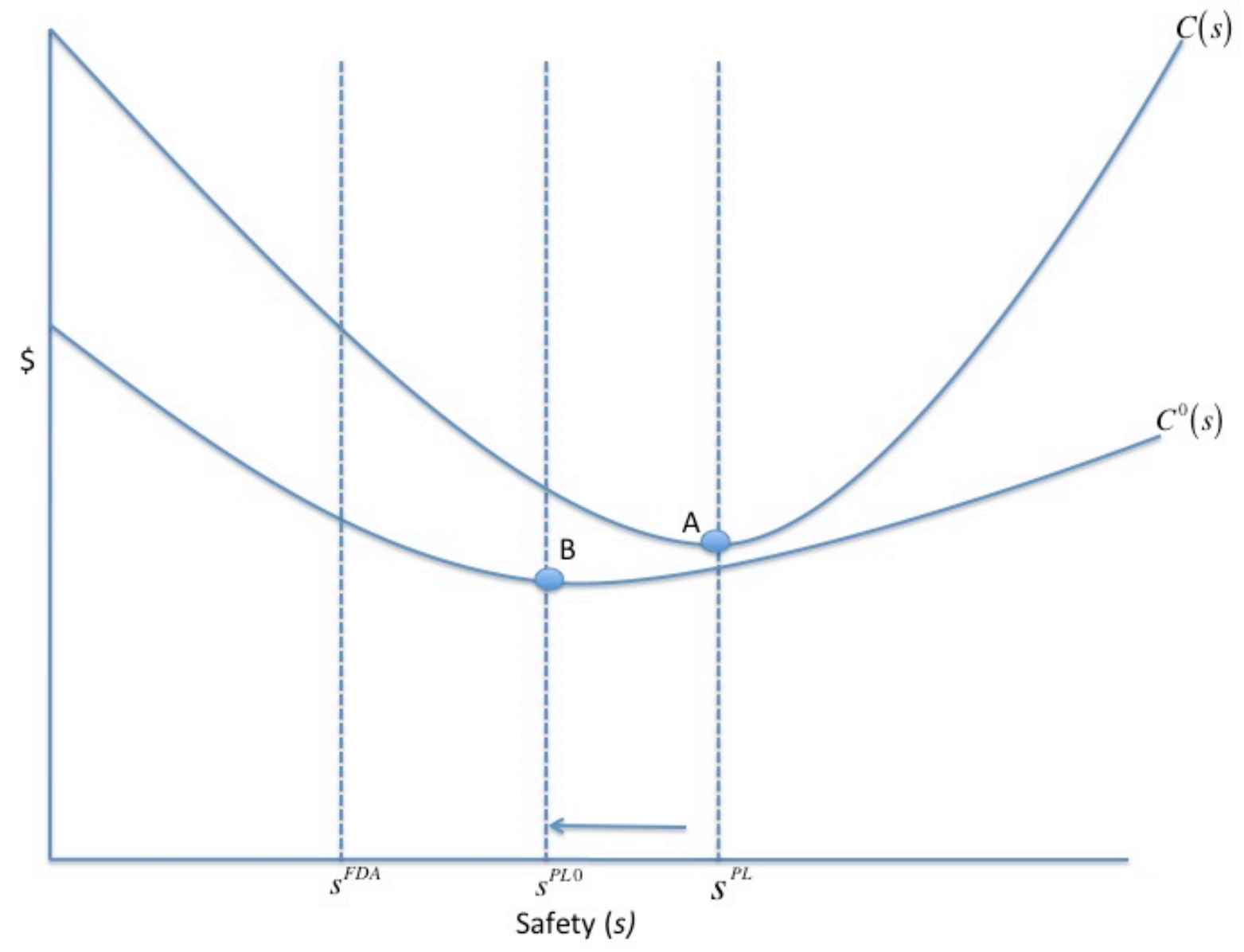

The level of safety mandated by the FDA, $s^{F D A}$, may lie to the left or to the right of the level of safety induced by liability $s^{P L}$, depending on whether FDA safety levels are binding. Consider the first case, as shown in figure 3. In this case the level of safety mandated by the 
FDA is not binding on firms, so they will provide safety $s^{P L}$ in the absence of a product liability exemption and $s^{P L 0}$ with the exemption. In this case, the welfare effect of the exemption is ambiguous, as the exemption lowers marginal costs and price, but also safety.

On the other hand, suppose that the safety mandated by the FDA lies to the right of $s^{P L}$, as shown in Figure 4. In this case, the level of safety mandated by the FDA is binding on firms, they will provide $s^{F D A}$ with or without the reduced level of liability. In this case, the preemption raises welfare by lowering marginal costs from point $\mathrm{C}$ to point $\mathrm{D}$, while having no effects on safety.

Figure 4 - Product Liability Exemption and Social Welfare : Binding FDA

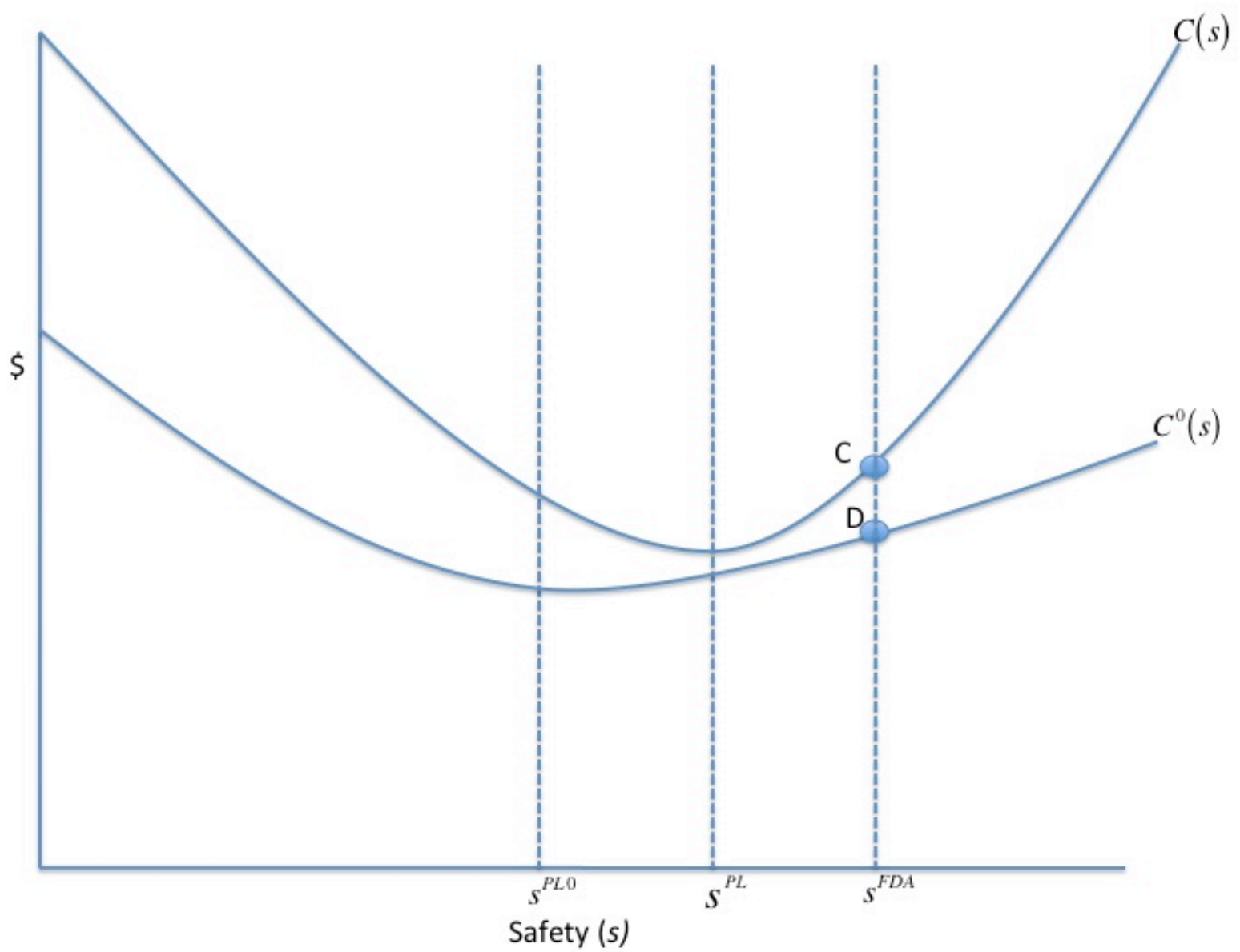


This analysis suggests that the pre-emption doctrine has the potential to increase welfare in the case where the presence of the FDA is binding on firms. Intuitively, product liability in general affects welfare by inducing firms to provide safe drugs and by raising prices, thereby reducing overconsumption by uninformed consumers. When the level of safety mandated by the FDA is binding, the agency mitigates the beneficial effects of product liability. Since the level of safety is binding, product liability has no additional effect on safety. And since consumers are informed, there is no need for a tax to reduce overconsumption. Since the agency's actions duplicate those of product liability, the latter simple acts as a tax that raises prices and inefficiently restricts access. It is worth reiterating that two components of FDA regulation drive this result. The first is that the FDA verifies and therefore informs consumers about safety. As previously discussed, with uninformed consumers, price increases due to product liability may actually be socially desirable, but with informed consumers these price increases reduce welfare. The second is that under the FDA, consumers are still uninformed or at least underestimate the damages the receive, so that price increases from product liability actually reduce output.

Several additional points are worth noting. First, since our discussion makes no assumptions on whether the level of safety chosen by the FDA is first- or second- best, our fundamental result holds: as long as the FDA mandated level of safety is binding, liability reductions will increase welfare, regardless of whether the FDA's choice is socially optimal. Second, product liability serves as a form of forced product insurance by raising price for all patients and compensating those who suffer harm. The effect of a removing product liability, therefore, is to eliminate this source of insurance for patients, which could reduce welfare if patients are risk averse. However, this loss could be averted if it is possible for patients to purchase insurance from third party providers or the government, as in the case of the vaccines, 
which we discuss in the next section. Moreover, to the degree that the liability system inefficiently compensates patients - for example, because of high legal and administrative costs, patients may be better off self insuring or obtaining insurance through third parties. 


\section{Section 4: A Case Study of Recent Drug Liability Limitations}

In this section, we consider a case study of the price- and safety effects of the National Vaccine Injury Compensation Program, which sharply reduced vaccine manufacturers' legal liability by creating a patient compensation fund supported by excise taxes on vaccine users. As discussed in the previous section, if FDA regulations are binding on vaccine makers, then a product liability exemption could reduce prices without affecting safety. Since the National Vaccine Injury Compensation Program shielded vaccine makers from the larger liability risk before the program, it serves as a useful case study of whether a product liability exemption would impact price and safety. Section 4.1 provides background on the program, while section 4.2 details our analysis.

\section{1: Background on the National Vaccine Injury Compensation Program}

Vaccines are credited with sharply reducing morbidity from several diseases, such as pertussis, polio, and tetanus (CDC, 1996). Currently, vaccinations for diphteria, pertussis, tetanus, measles, mumps, rubella, and polio are required for children attending kindergarten or middle school in all 50 states, and most states require vaccinations against hepatitis B and varicella zoster (chicken pox) virus as well. In addition to these required vaccines, several optional vaccines also exist for childhood and adult diseases, such as Hepatitis $\mathrm{C}$ and influenza.

Although vaccines are generally safe, as with all drugs, there is the potential for adverse side effects. For example, the pertussis vaccine (typically given in combination with vaccines for diptheria and tetanus) has long been associated with severe neurologic illnesses such as convulsions (Manning, 1994; CDC, 1996), while more recently, there has been controversy over the association between thiomersal, a preservative used in many vaccines, and autism. ${ }^{6}$ Prior to

\footnotetext{
${ }^{6}$ While the IOM, AMA, CDC, and FDA have stated there is no causal link between thiomersal and autism, to date, over 5,000 claims relating to autism have been filed with the National Vaccine Injury Compensation Program.
} 
the passage of the National Childhood Vaccine Injury Act in 1986, patients could sue vaccine manufacturers by alleging manufacturing defect, failures to provide proper warnings to the physician or patient, and/or failures to provide for safer alternatives (Ridgway, 1999). These lawsuits appear to have been substantial in the amount of damages relative to sales. For example, between 1980 and 1986, vaccine lawsuits alleged a total of $\$ 3.6$ billion in damages (Davis and Bowman, 1991).

Concerns that lawsuits might lead vaccine manufacturers to exit the market, or reduce the supply of vaccines led Congress to pass the National Childhood Vaccine Injury Act in 1986, which established the National Vaccine Injury Compensation Program (NVICP) on October 1, 1988. The NVICP requires payment of an excise tax for the vaccines covered, which funds a pool of money, the Vaccine Injury Trust Fund, used to compensate victims of adverse events. Prior to 1998, excise taxes were set at the estimated level of liability costs. For example, the excise tax for the diptheria-pertussis-tetanus vaccine, which contains the pertussis component associated with neurologic disease and lawsuits, was $\$ 4.56$, compared to only $\$ 0.06$ for the diptheria-tetanus vaccine. In 1998, the program was changed so that all vaccine recipients pay a common excise tax of $\$ 0.75$ per dose ${ }^{7}$ to fund the Vaccine Injury Trust Fund. If a patient suffers an adverse reaction after vaccination, he must first file a claim with the NVICP before proceeding to civil litigation against the vaccine manufacturer. In order to receive compensation, the patient's claim must establish that the vaccine caused the adverse event. Alternatively, the NVICP also maintains a table of vaccines, associated adverse effects, and time periods. If the patient's adverse effect is listed on the table and occurs within the specified time period, causality is presumed and the patient is entitled to compensation.

\footnotetext{
${ }^{7}$ A dose is defined per disease, so combination vaccines, count as more than one dose. For example, the excise tax for the Measles-Mumps-Rubella (MMR) vaccine is $\$ 2.25$, since it counts as having three doses.
} 
Claims with the NVICP are decided by Special Masters of the Court of Federal Claims. Patients who are found to have suffered an adverse event that was caused by a vaccine are entitled to recovery of damages for medical and other expenses, such as lost earnings. However, in the case of death, payments to the patient's estate are limited to $\$ 250,000$; this cap also applies to pain and suffering damages. As long as the claim meets certain minimal standards, legal expenses up to $\$ 30,000$ are reimbursed, regardless of the Special Master's decision. Acceptance of the Special Master's decision forecloses future legal claims against the vaccine manufacturer. If a patient disagrees with the decision, he can proceed to sue the manufacturer, but is barred from utilizing several approaches, such as lawsuits based on failures to warn.

The above description of the NVICP applies to patients who received a vaccine from 1988 onwards, and generally applies to patients who received a vaccine prior to 1988 , with a few differences. First, patients who received a vaccine prior to 1988 are allowed to bypass the NVICP and proceed directly to civil litigation. However, if they choose to file a claim with the NVICP, they must have done so by January 31,1991 . In addition, they face a limit of $\$ 30,000$ for attorney's fees, pain and suffering, and lost income. Instead of an excise tax, payments to these patients are funded by general revenues.

Table 1 provides a brief summary of the economic costs of the program. For several vaccines, the table lists the $\mathrm{CDC}$ price per dose which is the price available to organizations receiving $\mathrm{CDC}$ grant funds, such as state health departments, as well as the private sector price which is the price mandatorily reported by the manufacturer to the CDC. Table 1 also reports the excise tax for each vaccine which is fairly small relative to the private sector price for most of the vaccines. 
Table 1 - Prices and Excise Taxes for Selected Vaccines, 2010

\begin{tabular}{|c|c|c|c|c|}
\hline DISEASE & $\begin{array}{l}\text { BRAND } \\
\text { NAME }\end{array}$ & $\begin{array}{l}\text { CDC } \\
\text { PRICE/DOSE }\end{array}$ & $\begin{array}{l}\text { PRIVATE SECTOR } \\
\text { PRICE/DOSE }\end{array}$ & TAX \\
\hline \multicolumn{5}{|c|}{ Childhood } \\
\hline Diptheria/Pertussis/Tetanus & Tipedia & $\$ 13.25$ & $\$ 23.05$ & $\$ 2.25$ \\
\hline $\begin{array}{l}\text { Diptheria/Pertussis/Tetanus/ } \\
\text { Polio/Hepatitis B }\end{array}$ & Pediarix & $\$ 48.75$ & $\$ 70.72$ & $\$ 3.75$ \\
\hline Hepatitis A & Havrix & $\$ 12.75$ & $\$ 28.74$ & $\$ 0.75$ \\
\hline Hepatitis B & ENGERIX B & $\$ 9.75$ & $\$ 21.37$ & $\$ 0.75$ \\
\hline Measles, Mumps, and Rubella & MMRII & $\$ 18.30$ & $\$ 48.31$ & $\$ 2.25$ \\
\hline \multicolumn{5}{|c|}{ Adult } \\
\hline Hepatitis A & Havrix & $\$ 20.59$ & $\$ 63.10$ & $\$ 0.75$ \\
\hline Hepatitis B & ENGERIX-B & $\$ 26.70$ & $\$ 52.50$ & $\$ 0.75$ \\
\hline Diptheria/Tetanus & None & $\$ 13.25$ & $\$ 18.23$ & $\$ 1.50$ \\
\hline Influenza & Fluzone & $\$ 8.15$ & $\$ 9.72$ & $\$ 0.75$ \\
\hline
\end{tabular}

Table 2 provides summary statistics on inflation adjusted payments made by the NVICP between FY 1989 and FY 2009. The first column shows award amounts and attorney's payments for claims that were compensated by the NVICP, while the second column shows attorney's payments for claims dismissed by the NVICP. Between FY 1989 and 2009, the NVICP paid out a total of nearly $\$ 2.4$ billion for 4,581 claims. However, as previously noted, the NVICP reimburses legal costs even for dismissed claims, as long as minimal standards are met, so not all of these payments were made for successful claims against the Program. For compensable claims, the average award was roughly $\$ 1$ million, of which roughly $\$ 36,000$ was used for attorney's fees. ${ }^{8}$ The program paid an average of roughly $\$ 23,000$ for attorney's fees associated with dismissed claims.

\footnotetext{
${ }^{8}$ We previously stated that the NVICP caps attorney's fees at $\$ 30,000$ in nominal terms; the reason why this average is higher is due to discounting and adjusting for inflation.
} 
Table 2 - Summary Statistics on Payments Made by the NVICP, FY 1989-FY2009

\begin{tabular}{||l|l|l||}
\hline & COMPENSABLE CLAIMS & DISMISSED CLAIMS \\
\hline Total Number of Payments & 2,355 & 2,226 \\
\hline Total Payments & $\$ 2,411,085,611$ & $\$ 51,794,790$ \\
\hline Average Payment per Claim & $\$ 1,023,815.55$ & $\$ 23,268$ \\
\hline Average Award per Claim & $\$ 988,019$ & $\mathrm{~N} / \mathrm{A}$ \\
\hline $\begin{array}{l}\text { Average Attorney's Fee per } \\
\text { Claim }\end{array}$ & $\$ 35,795$ & $\$ 23,268$ \\
\hline $\begin{array}{l}\text { Notes: All dollar amounts are in 2008 dollars. Source is January 20,2010 statistics report from the National Vaccine } \\
\text { Injury Compensation Program, available at http://www.hrsa.gov/vaccinecompensation/statistics report.htm. }\end{array}$ \\
\hline
\end{tabular}

\section{2: The Price and Safety Effect of the National Vaccine Injury Compensation Program}

Table 3 shows the nominal excise tax for each vaccine between 1988-1996 and the nominal price of the vaccine in 1988. Recall that between 1988 and 1996, the excise taxes for each vaccine were set to represent expected liability costs. Thus, Table 3 suggests significant variation in vaccine liability. The DT and OPV vaccines appear to have had low legal exposure, as excise taxes comprised between 3 to $8 \%$ of the 1988 prices. Conversely, the measles, mumps, rubella, MMR, and DTP vaccines appear to have had higher legal exposure, as the excise taxes accounted for $19-41 \%$ of their 1988 prices.

Table 3 - Vaccine Excise Taxes

\begin{tabular}{|c|c|c|c|}
\hline VACCINES & $\begin{array}{c}\text { 1988-1996 EXCISE } \\
\text { TAX }\end{array}$ & $\begin{array}{c}1988 \\
\text { PRICE }\end{array}$ & $\begin{array}{c}\text { EXCISE } \\
\text { TAX(\% OF } \\
\text { PRICE })\end{array}$ \\
\hline Measles & $\$ 4.44$ & $\$ 13.79$ & $32 \%$ \\
\hline Mumps & $\$ 4.44$ & $\$ 15.26$ & $29 \%$ \\
\hline Rubella & $\$ 4.44$ & $\$ 14.24$ & $31 \%$ \\
\hline MMR & $\$ 4.44$ & $\$ 23.23$ & $19 \%$ \\
\hline DTP & $\$ 4.56$ & $\$ 11.03$ & $41 \%$ \\
\hline DT & $\$ 0.06$ & $\$ 0.78$ & $7.7 \%$ \\
\hline OPV & $\$ 0.29$ & $\$ 8.67$ & $3.3 \%$ \\
\hline
\end{tabular}


Expanding on the work of Manning (1994), we begin by examining the prices of the DT and DTP vaccines before and after the NVICP. Comparing the prices of these two vaccines is particularly helpful, since they are essentially similar except for the Pertussis component of the DTP vaccine, which was the subject of numerous lawsuits over neurological adverse events. As Manning (1994) discusses, the prices of the DT and DTP vaccines were quite similar prior to 1982, when lawsuits were rare. For example, in 1975 one dose of DTP cost 76 cents and one dose of DT cost 74 cents, a difference that remained largely unchanged up until 1982. However, after 1982, when the number of lawsuits for adverse events for the Pertussis component began to rise sharply, the price of the DTP vaccine increased significantly compared to the price of the DT vaccine. Since the two vaccines are otherwise similar except for the presence of the Pertussis component and had similar prices prior to 1983, Manning (1994) interprets the post-1982 difference in the prices of the two vaccines as the cost of liability for the Pertussis component. At its peak in 1986 , the difference in the price of the two vaccines was $\$ 14.58$, and liability costs accounted for nearly 96 percent of the DTP vaccine's price.

Figure 5 plots the prices, net of excise taxes, for the DT and DTP vaccines between 1975 and 1995. 9 Prices from 1975 through 1986 are Blue Book and Red Book wholesale prices collected by Manning (1994) who did not collect data after the NVICP program was implemented. To assess the time trend surrounding this program, from 1987 and beyond, we used private-sector vaccine prices reported by drug manufacturers and published by CDC. We chose 1995 as the end date because DTP prices were no longer available past this point, as the vaccine was replaced with the DTaP vaccine, a safer version of the DTP vaccine which uses an acellular form of the Pertussis pathogen. Figure 5 suggests that not only did prices of DTP rise

\footnotetext{
${ }^{9}$ We performed similar analyses using prices inclusive of excise taxes; the results are similar to those shown here.
} 
with increased liability but they also fell after the introduction of the National Vaccine Injury Compensation Program in 1988 , with the price (net of taxes) falling from $\$ 11.78$ in $1988^{10}$ to $\$ 7.73$, a $34 \%$ decrease. Since price of the DT vaccine slightly rose during the same period, the fall in the price of the DTP is likely due to changes in liability, as opposed to changes in the costs of production or increased competition.

Figure 5 - Prices for the DTP and DT vaccines, 1975-1995

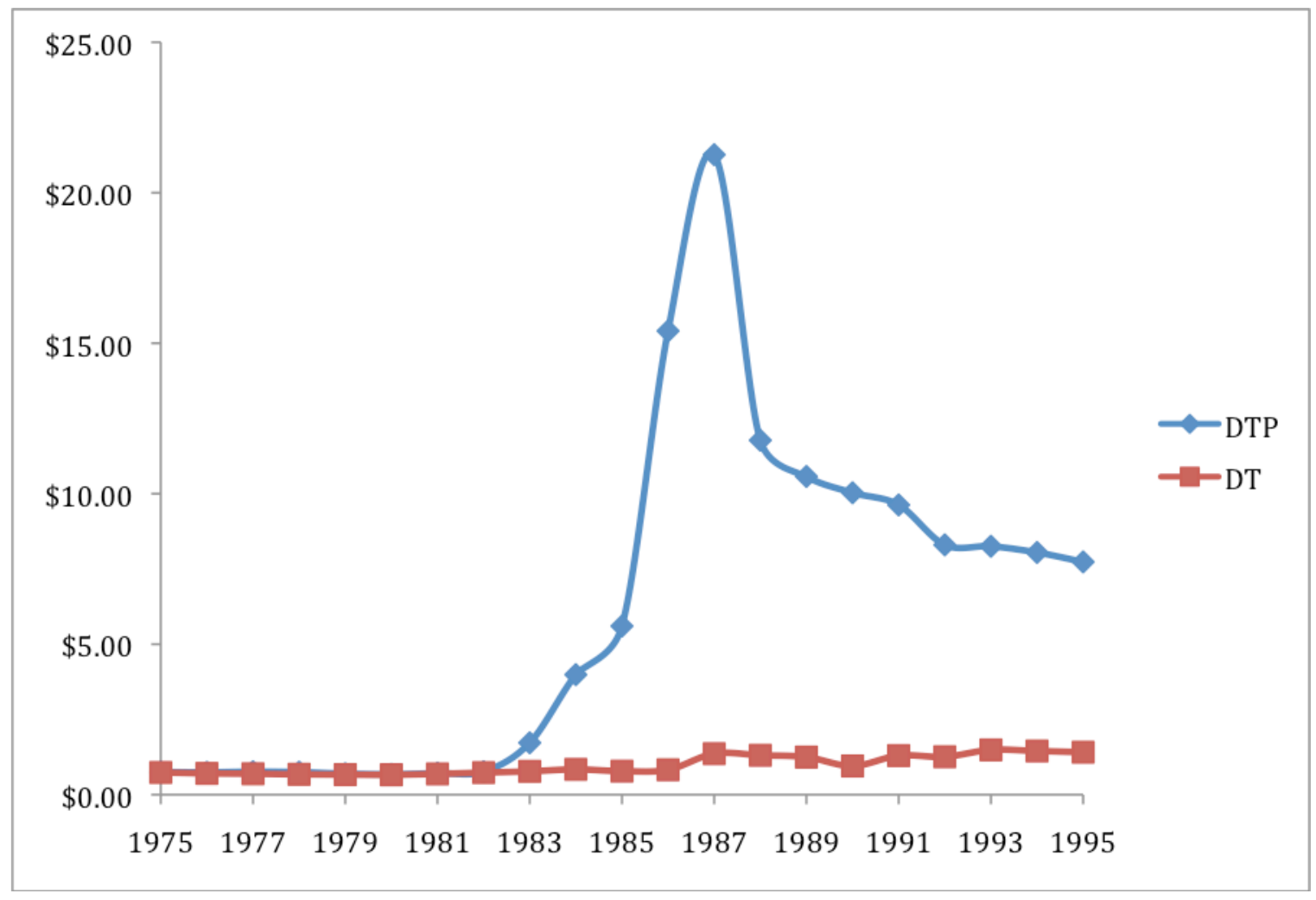

Notes: All values shown are in 2008 dollars. Sources described in text.

As shown in Figure 6, in addition to the DTP vaccine, the measles, mumps, rubella and MMR vaccines also appear to have faced high liability, given that that the excise tax accounted for a large percentage of each vaccine's price. Figure 6 plots the time series of the (net of tax) prices for each vaccine. As with the DTP vaccine, we find that the NVICP substantially lowered

\footnotetext{
${ }^{10}$ As stated in section 4.1, the NVICP took effect late in 1988 , so we use the 1988 price as the last price prior to the program's introduction.
} 
vaccine prices from their 1988 highs, with decreases ranging from $22 \%$ for the mumps vaccine to $31 \%$ for the measles vaccine. Taken together, Figures 5 and 6 suggest that the prices for heavily litigated vaccines fell significantly following the NVICP. As controls, Figure 7 plots the time series of prices (net of excise taxes) for two less heavily litigated vaccines, the DT and OPV vaccines. In contrast to the other more heavily litigated vaccines, we find that prices for these vaccines actually increased or stayed constant following passage of the NVICP, suggesting that the observed price decreases for heavily litigated vaccines were not due to other factors such as changes in market conditions.

\section{Figure 6 - Prices for the Measles, Mumps, Rubella, and MMR Vaccines, 1975-1995}

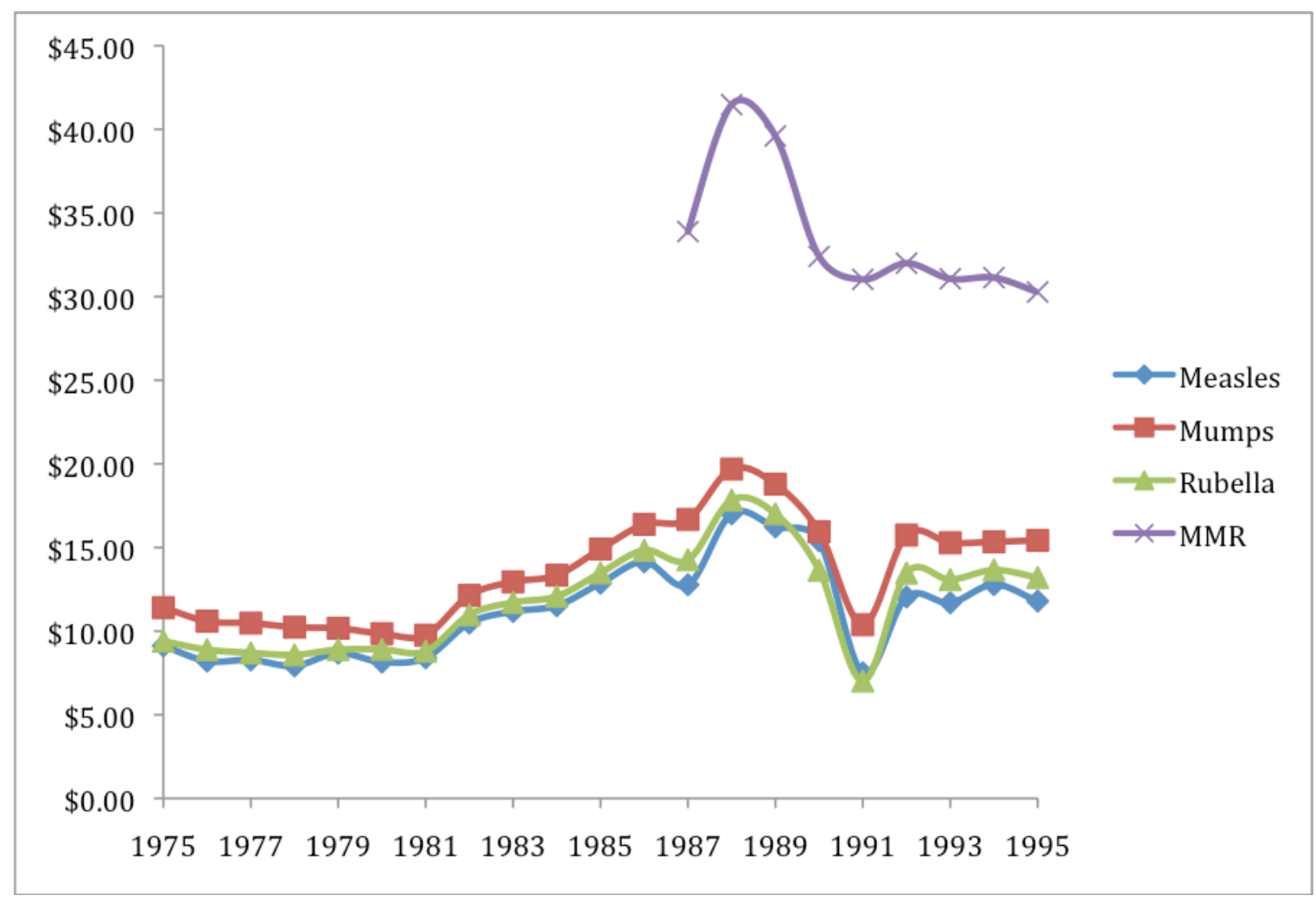

Notes: All values shown are in 2008 dollars. Sources described in text.

With information about the demand for vaccines, standard methods can be used to estimate the welfare gains from these price reductions induced by reduced liability. Specifically, 
consider when demand function has a constant price elasticity, so that the inverse demand function is

$$
p(x, s)=\left(\frac{x}{A(s)}\right)^{-\frac{1}{\varepsilon}}
$$

where $\varepsilon$ is the elasticity of demand and $A(s)$ is a shifter of demand based on safety $s$. With this demand specification can easily be shown that increase in welfare from a $z$ percent reduction in price is given by

$$
\Delta W=(1-z)^{1-\varepsilon}-1
$$

Figure 7 - Prices for the DT and OPV Vaccines, 1975-1995

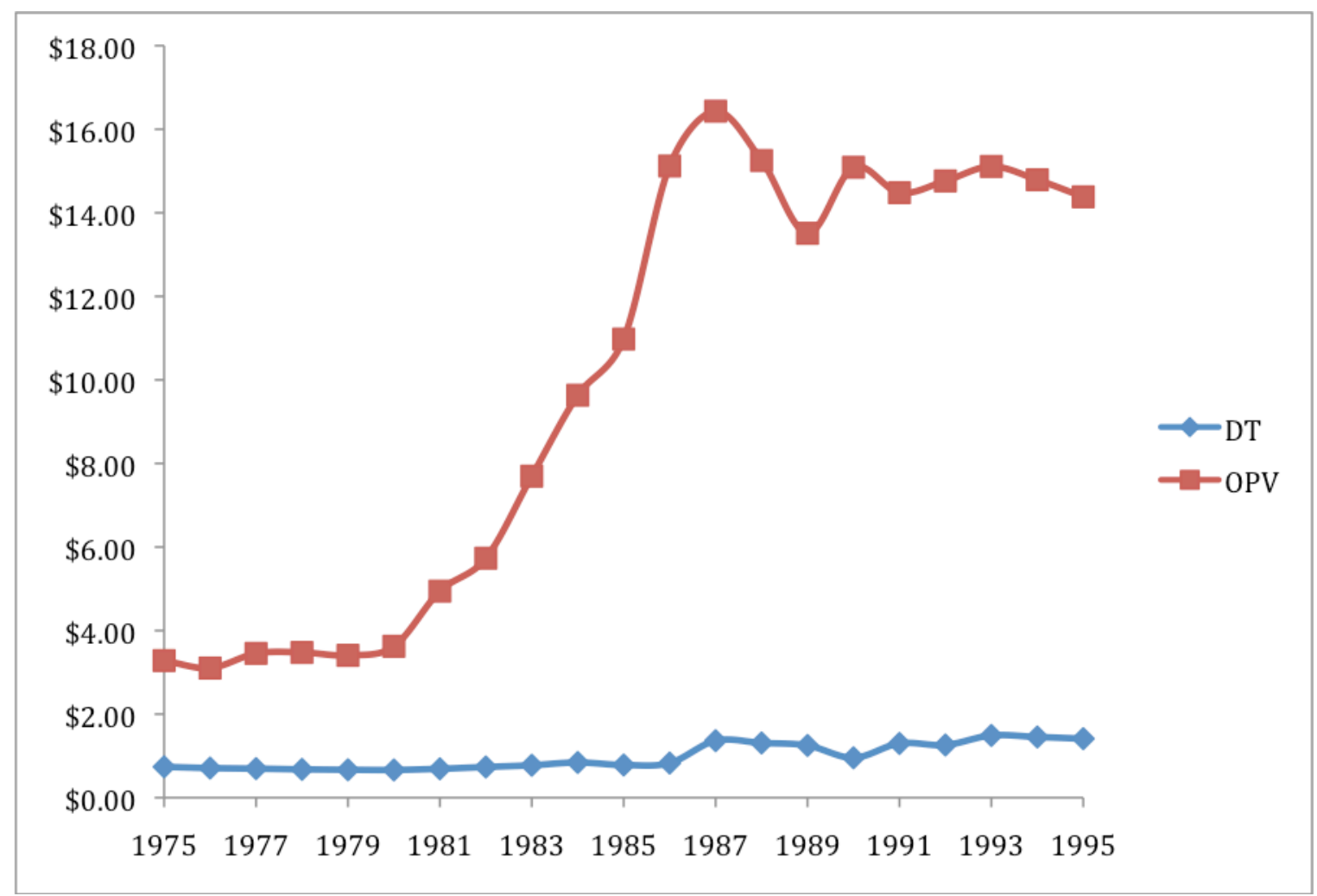

Notes: All values shown are in 2008 dollars. Sources described in text.

We consider an elasticity of 1.25, based on Philipson and Sun (2008). They utilize patent expiration evidence (Grabowski and Vernon, 1992; Berndt, Cockburn, and Griliches, 1996; 
Caves, Whinston, and Hurwitz, 1991), which implicitly estimates the demand elasticity for drugs by from supply-induced price-reductions from patent expiry. This elasticity of demand differs from the co-pay elasticity of demand estimated by others (Goldman, Joyce, and Karaca-Madic, 2006; Goldman, Joyce, and Zheng, 2007), because the latter is the elasticity of demand from patients who already have insurance, and only need to pay their insurance co-pay for the drug. Our elasticity of demand is the elasticity of demand facing the manufacturer, which takes into account the demand for health insurance itself and other factors as well.

Given an elasticity of 1.25 , Figure 8 shows the social surplus increases ( $\Delta W$ from equation 10) for the DTP vaccines, based on prices decreases from their peak values in each year of the NVICP. Overall, we find that the NVICP has substantial effects on consumer and producer surplus by lowering vaccine prices. For example, our results suggest that in 1995, the DTP vaccine was $34 \%$ lower than its pre-NVICP price, suggesting an increase in social surplus of $11 \%$.

Although Figure 8 shows that the NVICP likely had large effects on social welfare by reducing prices and increasing access, these gains must be balanced against any reductions in vaccine safety. There are two margins along which the NVICP may have affected safety. The first is on vaccines marketed before the program's implementation. Since the design of these vaccines did not change after the program, there was likely no change in safety for those vaccines. ${ }^{11}$ Thus, the NVICP appears to have unambiguously raised welfare in the case of the vaccines discussed above.

\footnotetext{
${ }^{11}$ This concerns design effects. If there are safety issues in manufacturing that are affected by liability, they may be affected after the product has been invented.
} 


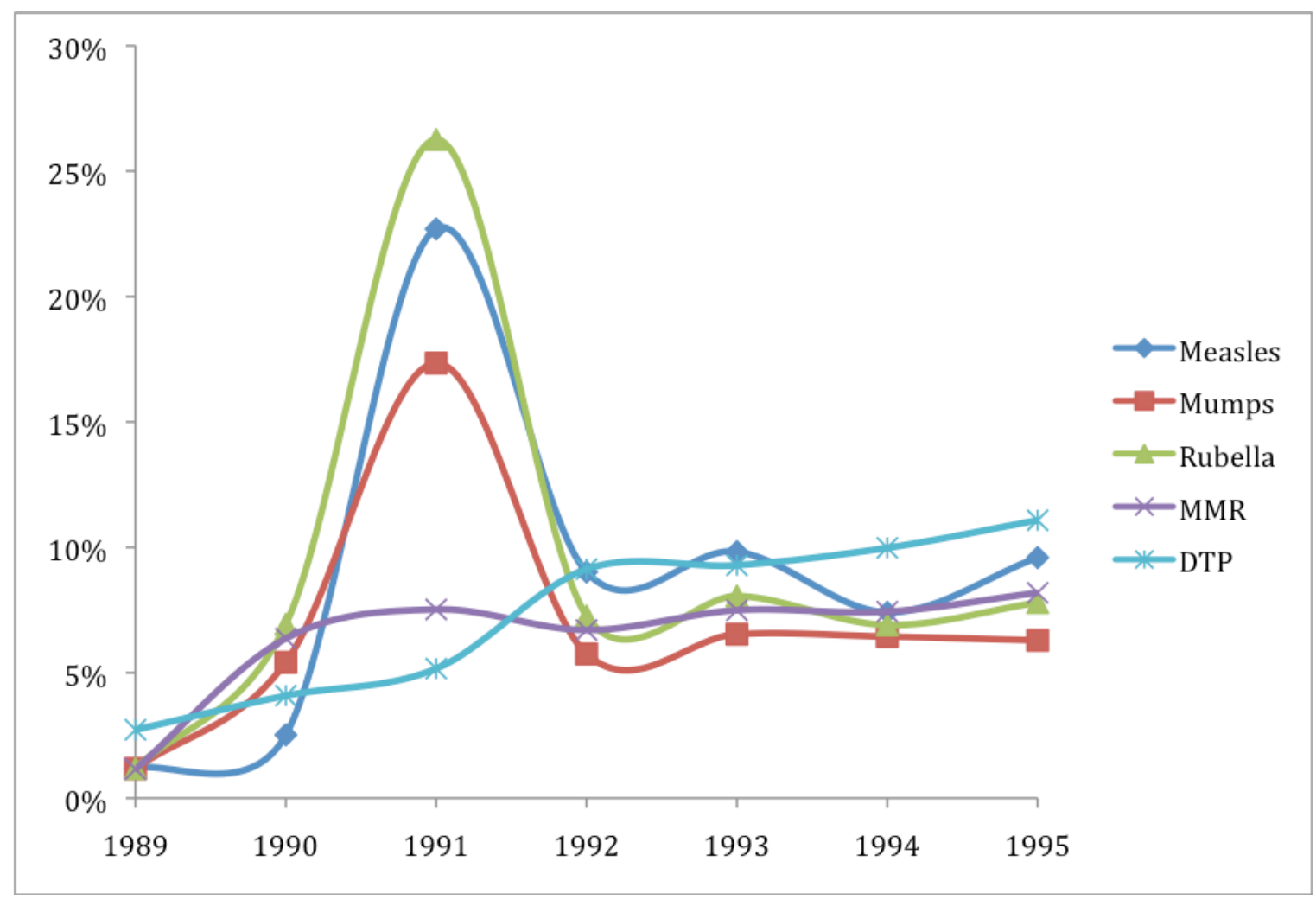

Notes: All values shown are in 2008 dollars. Source is author's calculations, as described in text.

The second margin is on vaccines marketed after the program's implementation, as the NVICP may have given firms incentives to market less safe vaccines. As one approach for looking at this issue, we examined the incidence of reported adverse events to the vaccines listed in Table 4. These vaccines were chosen because they comprise the recommended list of vaccinations for children, as given by the CDC. Table 4 also reports the recommended ages of administration for each vaccine, and the date each vaccine entered the market.

To estimate the incidence of adverse events, we used the Vaccine Adverse Event Reporting System (VAERS), which has collected reports on adverse events from immunizations since 1990. The VAERS consists of self-reported incidents of adverse events, from vaccine 
manufacturers $(42 \%)$, health care providers $(30 \%)$, state immunization programs $(12 \%)$, patients $(7 \%)$, and other sources $(9 \%)$. It is important to reiterate that these events are self reported, and that VAERS makes no effort to identify whether the vaccine actually caused the adverse event. Table 5 shows the total number of adverse events reported to VAERS for each vaccine between 1990 and 2006. To obtain the incidence, we divided the number of adverse events by the total number of children in the recommended ages during the periods for which the vaccine was available, using US Census data on population estimates by single years of age between 1990 and 2006. Since the Census only reports population by single years of age, we rounded the recommended ages listed in Table 4 up to the nearest whole year.

Overall, our results suggest that the newer vaccines are not less safe than vaccines introduced prior to the NVICP. For the five vaccines introduced prior to the NVICP, the mean number of adverse events per 100,000 doses is 15.4 (s.d. 10.8), while for the eight vaccines introduced after the NVICP, the mean probability of an adverse event is 9.28 (s.d. 9.03). Although the incidence of adverse events is slightly lower with the newer vaccines, the difference between the groups is not statistically significant $(\mathrm{p}<0.2)$. 
Table 4 - Incidence of Adverse Events for Childhood Vaccines, 1990-2006

\begin{tabular}{|c|c|c|c|c|c|}
\hline VACCINE & $\begin{array}{c}\text { YEAR OF } \\
\text { INTRODUCTION }\end{array}$ & $\begin{array}{c}\text { RECOMMENDED } \\
\text { AGES }\end{array}$ & $\begin{array}{l}\text { NUMBER } \\
\text { OF } \\
\text { ADVERSE } \\
\text { EVENTS }\end{array}$ & $\begin{array}{c}\text { TOTAL } \\
\text { POPULATION } \\
\text { AT RISK } \\
\text { (MILLIONS) }\end{array}$ & $\begin{array}{c}\text { NUMBER } \\
\text { OF } \\
\text { ADVERSE } \\
\text { EVENTS } \\
\text { PER } \\
100,000 \\
\text { DOSES }\end{array}$ \\
\hline \multicolumn{6}{|c|}{ Vaccines Introduced Prior to NVICP } \\
\hline DTP & 1950 & $<=6 y$ rs & 20,221 & 465 & 4.35 \\
\hline Poliovirus & 1964 & $2-15 \mathrm{mos}, 4-6 y$ & 23,574 & 332 & 7.10 \\
\hline Hepatitis B & 1981 & $<=18 \mathrm{mos}$ & 29,741 & 199 & 19.0 \\
\hline $\begin{array}{c}\text { Haemophilus } \\
\text { B }\end{array}$ & 1985 & $<=15 \mathrm{mos}$ & 37,822 & 199 & 14.9 \\
\hline MMR & 1987 & 12-15mos, 4-6y & 41,866 & 133 & 31.6 \\
\hline \multicolumn{6}{|c|}{ Vaccine Introduced After NVICP } \\
\hline Influenza & Annually & $\begin{array}{c}\text { Children 6mos- } \\
18 y ;\end{array}$ & 28,203 & 1,262 & 2.23 \\
\hline DTaP & 1994 & $<=6 y r s$ & 34,760 & 412 & 8.43 \\
\hline Varicella & 1995 & $12-15 \mathrm{mos}, 4-6 y$ & 28,407 & 94 & 30.4 \\
\hline $\begin{array}{c}\text { Pneumococcal } \\
\text { (Conjugate) }\end{array}$ & 2000 & $<=15 \mathrm{mos}$ & 13,268 & 166 & 7.99 \\
\hline $\begin{array}{l}\text { Meningococcal } \\
\text { Vaccine }\end{array}$ & 2001 & $11-12 y$ & 1,150 & 20 & 5.68 \\
\hline Hepatitis A & 2005 & $12-24 \mathrm{mos}$ & 6,699 & 98 & 6.85 \\
\hline Rotavirus & 2006 & $6-14 \mathrm{wks}$ & 710 & 36 & 1.98 \\
\hline $\begin{array}{c}\text { Human } \\
\text { Papillomavirus }\end{array}$ & 2006 & $11-12 y$ & 429 & 4 & 10.78 \\
\hline
\end{tabular}

Overall, then, our analysis suggests that the NVICP has not resulted in more dangerous vaccines. However, it is useful to note several limitations to our analysis. First, as described above, the VAERS may not provide a completely accurate measure of the number of adverse events. On the one hand, VAERS may understate the true number of adverse events, since it the data is self-reported; however, since VAERS makes no attempt to verify whether a vaccine did cause a reported adverse event, it may also overstate the true of events. In addition, our measure of the total population at risk includes only the number of children who were at the recommended age for the vaccine. This value may understate the true number of patients 
receiving the vaccine to the degree that vaccinations are delayed and therefore received at later ages. Conversely, this approach may understate the number of patients taking the vaccine if compliance is not perfect. However, to the degree that these shortcomings equally affect the vaccines in our sample, they would not significantly affect our results. Overall, then, we find that the NVICP likely increased welfare by lowering prices, without affecting safety.

An additional benefit of the NVICP is that it may have compensated patients more efficiently than the product liability system. First, data from Manning (1994) and the NVICP itself suggest that the program did not, on average, reduce compensation to persons suffering vaccine injury. According to Manning (1994), between 1980 and 1985, prior to the passage of the NVICP, the average amount paid for vaccine injury claims was $\$ 420,185$ (in 2008 dollars). As shown in Table 2, since the NVICP, the average amount paid per compensated claim is roughly \$1 million. While we cannot exclude the possibility that the nature of injuries and the probability of receiving compensation may have changed over time, these findings provide some evidence that compensation to injured patients has not fallen as a result of the NVICP. Moreover, Manning (1994) estimates that prior to passage of the NVICP, the cost of compensating a patient $\$ 1$ cost firms between $\$ 7-\$ 22$ in legal/administrative costs. By contrast, between FY 1989-FY2009 the NVICP compensated patients a total of \$2.3 billion while paying out roughly $\$ 140$ million in attorney’s costs. While not definitive, since this latter figure leaves out the administrative costs of running the NVICP as well the legal costs associated with any cases that did go to trial, these findings suggest that the NVICP compensated patients more efficiently than the product liability system. 


\section{Section 5: Concluding Remarks}

Our analysis examined the value of liability reductions in the presence of FDA regulations to ensure medical product safety. When one mechanism dominates the other in providing safety then there may be efficiency gains in eliminating the second. We argued that this may be the case in medical product safety when FDA safety levels are binding on firms so that reductions in liability do not affect safety but lowers prices and hence expand output and access to medicines. We discussed qualitative evidence for a case study of the National Vaccine Injury Compensation Program which suggested that prices but not safety fell after the government reduced liability. Although pre-emption is an obvious example of liability reduction, and one which has been the subject of recent Supreme Court decisions, it is useful to point out that our theoretical results also extend to other forms of liability reduction, such as caps on punitive damages and damage caps.

The fact that the NVICP program displayed these safety and price patterns is consistent with other observations that the level of safety mandated by the FDA is binding on manufacturers. First, because firms seldom exceed the safety investments required by the FDA, such as performing more clinical trials than what the agency demands (Garber, 1993). Second, trials in which a firm is alleged to have violated FDA standards or misled the FDA are rare (Garber, 1993). Given the strong possibility that the FDA mandates a higher level of safety than firms would be willing to provide under product liability alone, our analysis suggests that the adoption of the pre-emption doctrine could significantly increase welfare by reducing prices.

Our analysis stresses the substitutability between FDA and liability and therefore suggests the lowest cost substitute to minimize costs. There are two other reasons why FDA may be the best substitute to minimize costs. The first is that the ex-ante regulations of FDA may 
tradeoff the safety of a product with the adverse R\&D effects it may have by lengthening the time and cost to bring a product to market. Ex-post court decisions are unlikely to take into account this tradeoff at all. This is particularly true with lay juries who are spending other peoples' money to compensate victims of product failures ex-post with any deliberation about the R\&D effects involved. The second argument against government provided product liability is that the market can, and often does, provide warranties by itself if welfare enhancing. Product liability is essentially a mandatory warranty that the market has chosen not to provide, and it is not clear what market failure this mandatory warranty solves.

Recent policies and court decision have tended towards reducing firms' legal liability. For example, the recent inclusion of the pre-emption doctrine in the Federal Register, as well as the Supreme Court's decision in Riegel v. Medtronic, which upheld the doctrine in the case of medical devices, represent recent legislative and executive branch policies that reduced firms' liability. However, in Wyeth v. Levine, the Court ruled 5-4 that preemption does not apply to pharmaceuticals. While there may or may not be good legal justification for applying preemption to medical devices and not to pharmaceuticals, our analysis suggests that the economic rationale for doing so is less clear.

There are several useful extensions to our analysis which we believe are of further interest. First, we examined the impact of safety regulation on static efficiency. Since regulation affects firms' profits and therefore their incentives to invest in R\&D, further work should also try to determine what types of regulatory regimes maximize dynamic welfare taking into account innovation incentives. For example, in the case of the NVICP, firms may have had less incentive to invest in safety for a given vaccine, since the Program reduced their legal liability. However, by lowering costs and increasing profits, the Program may have increased R\&D efforts more 
generally. It may also be the case that vaccine R\&D may be less responsive to reductions in liability compared to other markets, such as drugs and devices, because vaccine manufacturers operate in a monopsony market and therefore face lower profits. Second, further work should attempt to further quantify the discussed welfare gains from pre-emption. The model we developed suggests that potential welfare gains are larger when liability accounts for a significant fraction of marginal costs. Given that drugs and vaccines are typically thought to have low marginal costs of production, it likely that even small legal costs can account for a significant fraction of overall marginal costs. The larger are the price reductions from preemption, the larger gains in access and welfare. Third, it would be interesting to examine the interplay of the FDA and product liability in affecting off-label drug use, such as whether firms may be less likely to invest in off-label studies, if doing so leads to increased liability exposure. Lastly, we did not discuss the potential complimentary roles of FDA and product liability, in which different forms of product safety is enhanced by the two different public interventions. For example, liability may make up for poor enforcement of the FDA. When there are such complementarities pre-emption will still lead to price reductions but may now also induce a reduction in safety.

Overall, we hope that future theoretical and empirical analysis will better address the rationales for the dual nature of safety regulation and enforcement by governments around the world, and increase our understanding of when it adds costs larger than the benefits compared to using one form alone or compared to using the market itself. 


\section{References}

Berndt, E., Cockburn I., and Griliches, Z. 1996. "Pharmaceutical Innovations and Market Dynamics: Tracking Effects on Price Indexes for Antidepressant Drugs." Brookings Paper on Economic Activity, Microeconomics, 1996: 133-199.

Calfee, J. 2006. "Striking a Balance : Drug Labeling and the FDA." AEI Online, available at http://www.aei.org/publications/pubID.23868/pub_detail.asp.

Calfee, J. 2008. Written Testimony before the United States House of Representatives Committee on Oversight and Government Reform, May 14.

Calfee J., Berndt E., Hahn R., et al. 2008. Amicus Brief to the Supreme Court in Wywth v. Levine

Caves, R., Whinston, M., and Hurwitz, M. 1991. "Patent Expiration, Entry, and Competition in the U.S. Pharmaceutical Industry." Brookings Papers on Economic Activity, Microeconomics, 1991:1-61.

Goldman, D., Joyce, G., and Karaca-Mandic, P. 2006. "Varying Pharmacy Benefits with Clinical Status: The Case of Cholesterol-Lowering Therapy." American Journal of Managed Care 12(1):21-38.

Goldman, D., Joyce, G., and Zheng, Y. 2007. "Prescription Drug Cost-Sharing: Associations with Medication and Medical Utilization and Spending, and Health.” JAMA 29(1):61-69.

Grabowski, H., Vernon, J., and Thomas, L. 1978. "Estimating the Effects of Regulation on Innovation: An International Comparative Analysis of the Pharmaceutical Industry." Journal of Law and Economics, 21(1): 133-163.

Curfman, G., Morrisey, S., and Drazen, J. 2008. "Why Doctors Should Worry About Pre-emption." New England Journal of Medicine 359:1-2.

Davis, T., Bowman, C. 1991. "No-Fault Compensation for Unavoidable Injuries: Evaluating the National Childhood Vaccine Injury Compensation Program." University of Dayton Law Review 16(2):277-321.

Garber, Steven. 1993. Product Liability and the Economics of Pharmaceuticals and Medical Devices. RAND Report R-4285-ICJ, RAND, Santa Monica, CA.

Glantz L., and Annas, G. 2008. "The FDA, Pre-emption, and the Supreme Court." New England Journal of Medicine 358(18):1883-1885. 
Kessler, D. and Vladeck, D. 2008. “A Critical Assessment of the FDA's Efforts to Preempt Failure-to-Warn Claims." Georgetown Law Journal 96:462-495.

Manning, R. 1994. "Changing Rules in Tort Law and the Market for Childhood Vaccines." Journal of Law and Economics 37(1):247-275.

Manning, R. 1997. "Product Liability and Prescription Drug Prices in Canada and the United States." Journal of Law and Economics 40(1):203-243.

Philipson, T. J. and Sun, E. 2008. "Is the Food and Drug Administration Safe and Effective?" Journal of Economic Perspectives 22(1): 85-102.

Polinsky, A.M. and Shavell, S. 2007. "Public Enforcement of Law." In Handbook of Law and Economics, ed. A.M. Polinsky and S. Shavell. Elsevier.

Ridgway, D. 1999. "No-Fault Vaccine Insurance: Lessons from the National Vaccine Injury Compensation Program." Journal of Health Politics, Policy, and Law 24(1):59-90.

Shavell, S. 2007. "Liability for Accidents." In Handbook of Law and Economics, ed. A.M. Polinsky and S. Shavell. Elsevier.

United States Centers for Disease Control (CDC). 1996. "Update: Vaccine Side Effects, Adverse Reactions, Contraindications, and Precautions." Morbidity and Mortality Weekly Report 45:no. RR-12.

United States Council of Economic Advisors. 2002. Who Pays for Tort Liability Claims? An Economic Analysis of the U.S. Tort Liability System. Washington, D.C. 